\title{
Physiological coagulation can be maintained in extracorporeal circulation by means of shed blood separation and coating
}

\author{
Johannes M. Albes, MD \\ Ingeborg M. Stöhr, MD \\ Mirko Kaluza, BS ${ }^{\mathrm{a}}$ \\ Annelie Siegemund, MD \\ Dirk Schmidt, MD ${ }^{\mathrm{c}}$ \\ Rüdiger Vollandt, $\mathrm{PhD}^{\mathrm{d}}$ \\ Thorsten Wahlers, MD ${ }^{\text {a }}$
}

\footnotetext{
From the Department of Cardiothoracic and Vascular Surgery, ${ }^{a}$ Friedrich-Schiller-University-Hospital, Jena, Germany; Department of Internal Medicine, ${ }^{\mathrm{b}}$ Leipzig University, Leipzig, Germany; Department of Clinical Chemistry, ${ }^{\mathrm{c}}$ Friedrich-SchillerUniversity-Hospital, Jena, Germany; and Department of Medical Statistics, Informatics, and Documentation, ${ }^{\mathrm{d}}$ FriedrichSchiller-University Hospital, Jena, Germany

The laboratory analysis of the specific coagulation and fibrinolysis parameters TATc, PAPc, and F1+2 was financially supported by Sorin Inc, Mirandola, Italy.

Received for publication Sept 26, 2002; revisions requested Feb 10, 2003; revisions received June 16, 2003; accepted for publication June 18, 2003.

Address for reprints: Johannes M. Albes, MD, Department of Cardiovascular Surgery, Heart Center Brandenburg, Ladeburger Str 17, 16321 Bernau-Berlin, Germany (E-mail: j.albes@immanuel.de).

J Thorac Cardiovasc Surg 2003;126: 1504-12

Copyright () 2003 by The American Association for Thoracic Surgery

$0022-5223 / 2003 \$ 30.00+0$

doi:10.1016/S0022-5223(03)00958-9
}

Objective: Conventional extracorporeal circulation results in an activation of coagulation cascades. Coating of extracorporeal circulation tubes as well as avoidance of shed blood recirculation have been shown to reduce these phenomena. We evaluated a new shed blood separation system (AVANT D 970) utilizing a coated cardiopulmonary bypass tube system (PHISIO).

Methods: Forty patients ( $62 \pm 10$ years) underwent isolated coronary revascularization. Four groups $(n=10 /$ group) were defined: no extracorporeal circulation, conventional uncoated extracorporeal circulation, uncoated extracorporeal circulation with shed blood separation, and coated extracorporeal circulation with shed blood separation. Thrombinantithrombin complex and free $\mathrm{Hb}$ were analyzed and statistically compared.

Results: Conventional extracorporeal circulation exhibited the highest intraoperative activation of coagulation (thrombin-antithrombin complex: extracorporeal circulation, $31.1 \pm 15.8 \mu \mathrm{g} / \mathrm{L}$; uncoated extracorporeal circulation with shed blood separation, $15.3 \pm 7.8 \mu \mathrm{g} / \mathrm{L}$; coated extracorporeal circulation with shed blood separation, $8.1 \pm 4.8 \mu \mathrm{g} / \mathrm{L}$; no extracorporeal circulation, $2.4 \pm 0.6 \mu \mathrm{g} / \mathrm{L} ; P<.05$ extracorporeal circulation vs all others) and red blood cell damage (free $\mathrm{Hb}$ : extracorporeal circulation, $16.8 \pm 11.4 \mu \mathrm{mol} / \mathrm{L}$; uncoated extracorporeal circulation with shed blood separation, $10.3 \pm 3.5 \mu \mathrm{mol} / \mathrm{L}$; coated extracorporeal circulation with shed blood separation, $6.8 \pm 2.9 \mu \mathrm{mol} / \mathrm{L}$; no extracorporeal circulation, $3.4 \pm$ $1.1 \mu \mathrm{mol} / \mathrm{L} ; P<.05$ extracorporeal circulation vs no extracorporeal circulation, coated extracorporeal circulation with shed blood separation). Coated extracorporeal circulation with shed blood separation showed only slight activation and cell trauma, which did not differ significantly from no extracorporeal circulation.

Conclusions: Combination of coating and avoidance of shed blood recirculation maintained physiological coagulation levels and markedly reduced red blood cell trauma in extracorporeal circulation procedures. These combined modalities may therefore offer an alternative for off-pump procedures in patients with contraindications for conventional extracorporeal circulation.

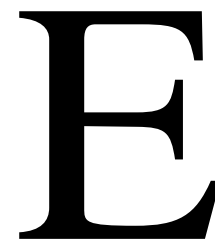

xtracorporeal circulation modalities induce a systemic inflammatory response. ${ }^{1}$ The complex pathomechanism is still not entirely understood. However, a variety of humoral as well as cellular reactions has been identified thus far. ${ }^{1}$ Among these, mechanical alteration of corpuscular blood elements as well as humoral response due to the contact of the blood with foreign surfaces and mechanical propelling devices are considered to be significant contributors. ${ }^{1-3}$ Furthermore, the duration of 
extracorporeal circulation and the degree of activation exhibit a direct correlation. ${ }^{4}$ Humoral and cellular factors can interact in a complex fashion by means of complement activation, induction of arachidonic acid metabolism, cytokine liberation, and initiation of coagulation-fibrinolytic cascades. ${ }^{1-5}$ Much effort was undertaken in recent years to reduce the damage caused by the heart-lung machine. ${ }^{3}$ The first success was achieved by means of coating of the involved components such as tubes, reservoir, and oxygenator. ${ }^{6}$ Among the recent developments, a phosphorylcholine surface coating showed promising results and was therefore clinically introduced. ${ }^{7}$ Evidence showed that inflammatory agents develop in shed blood accumulated during cardiac procedures, which may well be able to enhance the inflammatory response when recirculated into the extracorporeal circuit. ${ }^{4,8}$ Therefore, a shed blood separation system implemented in a cardiotomy reservoir was developed to avoid direct recirculation. The purpose of this study was to evaluate the potential of phosphorylcholine coating and shed blood separation to reduce activation of coagulation-fibrinolytic cascades as one of the components of the inflammatory response during cardiac procedures, utilizing an otherwise conventional extracorporeal circulation system.

\section{Material and Methods} Demographic Data

Forty patients $(62 \pm 10$ years $)$ underwent isolated elective coronary revascularization for single-, double-, or triple-vessel disease. All patients had sinus rhythm and a preoperative ejection fraction of more than $35 \%$ and all exhibited normal renal and hepatic function (serum creatinine $<100 \mu \mathrm{mol} / \mathrm{L}$; prothrombin time $>$ $70 \%$ ). None of the patients was on anticoagulatory medication with coumarin, and all patients received chronic medication with acetylsalicylic acid until 7 days preoperatively (100 mg daily dose).

\section{Operation}

The patients were operated on according to clinical and morphological criteria. Conventional coronary revascularization with cardiopulmonary bypass (CPB) was performed for double- or triplevessel disease. Minimally invasive arterial revascularization (MIDCAB) without $\mathrm{CPB}$ was performed in patients with singlevessel disease. In all CPB patients the left internal thoracic artery and a respective number of vein grafts/anastomoses were used. All patients operated on with CPB underwent total median sternotomy, preparation, and harvesting of the left internal thoracic artery after the pleura was opened, combined with conventional open venous harvesting. In all MIDCAB patients the left internal thoracic artery was prepared via a left anterior thoracotomy and was anastomosed to the LAD with mechanical stabilization while the heart was beating.

\section{Study Protocol}

The study protocol was approved by the local ethical committee on human research. All patients who agreed to participate in this trial gave written informed consent. The patients with double- or triplevessel disease were randomly allocated to 1 of the CPB groups. The patients with single-vessel disease were uniformly allocated to the MIDCAB group. Four groups $(\mathrm{n}=10)$ were defined: noECC, MIDCAB; ECC, conventional extracorporeal circulation without coating and shed blood separation; ECCSBS, uncoated ECC with shed blood separation system; CECCSBS, coated ECC with shed blood separation system.

\section{Anesthesia}

All patients received general anesthesia, conventional intubation, and ventilation. MIDCAB patients received a double lumen tracheobronchial tube to perform intermittent unilateral ventilation. After premedication with benzodiazepine, general anesthesia was induced and maintained with propofol, skeletal muscle relaxation with pancuronium bromide, and volatile anasthetics (isoflurane). Standard monitoring was established. Prior to institution of CPB all patients received $400 \mathrm{IU} / \mathrm{kg}$ of body weight (BW) intravenous heparin and additional doses, if required, to maintain an activated clotting time (ACT) of over 400 seconds during CPB. ACT (automated coagulation timer ACT II; Medtronic HemoTec Inc, Englewood, NJ) was measured directly after initial heparin administration and every 20 minutes thereafter until the end of the procedure. Volatile anesthetics (Sevoflurane; Dräger AG, Bremen, Germany) were given via the heart-lung machine during extracorporeal circulation. MIDCAB patients received $100 \mathrm{mg} / \mathrm{kg} \mathrm{BW}$ heparin intravenously after left internal thoracic artery preparation. After completion of the anastomosis heparin was partially antagonized with $50 \mathrm{mg} / \mathrm{kg} \mathrm{BW}$ protamine.

\section{General Extracorporeal Circulation Modalities}

Extracorporeal circulation modalities (Stöckert SIII, Stöckert Instruments, Munich, Germany) comprised 3-point pressure monitoring (pre- and postoxygenator, arterial line; $\mathrm{x}$-trans; Smith Medical Inc, Kirchseeon, Germany) and online blood gas analysis (CDI 500; Terumo CVSE Inc, Borken, Germany). Priming consisted of 900 mL Ringer's solution, 400 mL HES 6\% (poly(O-2-hydroxyethyl-starch), $250 \mathrm{~mL}$ mannitol, $10000 \mathrm{U}$ heparin, 2 million $\mathrm{U}$ aprotinin, and $20 \mathrm{~mL} \mathrm{NaHCO}_{3}$. Extracorporeal circulation was instituted in all patients via a $24 \mathrm{~F}$ central aortic cannula (Jostra AG, Hirrlingen, Germany), a central 2-stage venous cannula 50/ 36-French (Stöckert Instruments), and a main circulatory roller pump (Stöckert Instruments). The blood was drained into a cardiotomy reservoir (AVANT Reservoir D970; Dideco Inc, Mirandola, Italy), pumped through a conventional oxygenator (AVANTOxygenator, Dideco Inc), and filtered (D734, Dideco Inc) back into the patient at a rate of $2.5 \mathrm{~L} / \mathrm{min} / \mathrm{m}^{2}$ body surface area. Shed blood suction was performed with a roller pump (Stöckert Instruments). Moderate hypothermia of $33^{\circ}$ to $34^{\circ} \mathrm{C}$ was employed. A regular vacuum suction was additionally used to clear the operative field. The system consisted of a disposable suction cannula and tube connected with a sterile heparinized chamber. The aspirated blood was processed in a cell saver, and debris and fat were removed by an integrated 200- $\mu \mathrm{m}$ filter (Compact A 75173, Dideco Inc). Electrical fibrillation was applied and the aorta was crossclamped. Antegrade cold blood cardioplegia (blood cardioplegia "Buckberg," cardioplegia systems with "CSC14," Dideco Inc) mixed from buffer solution and autologous blood circulating 


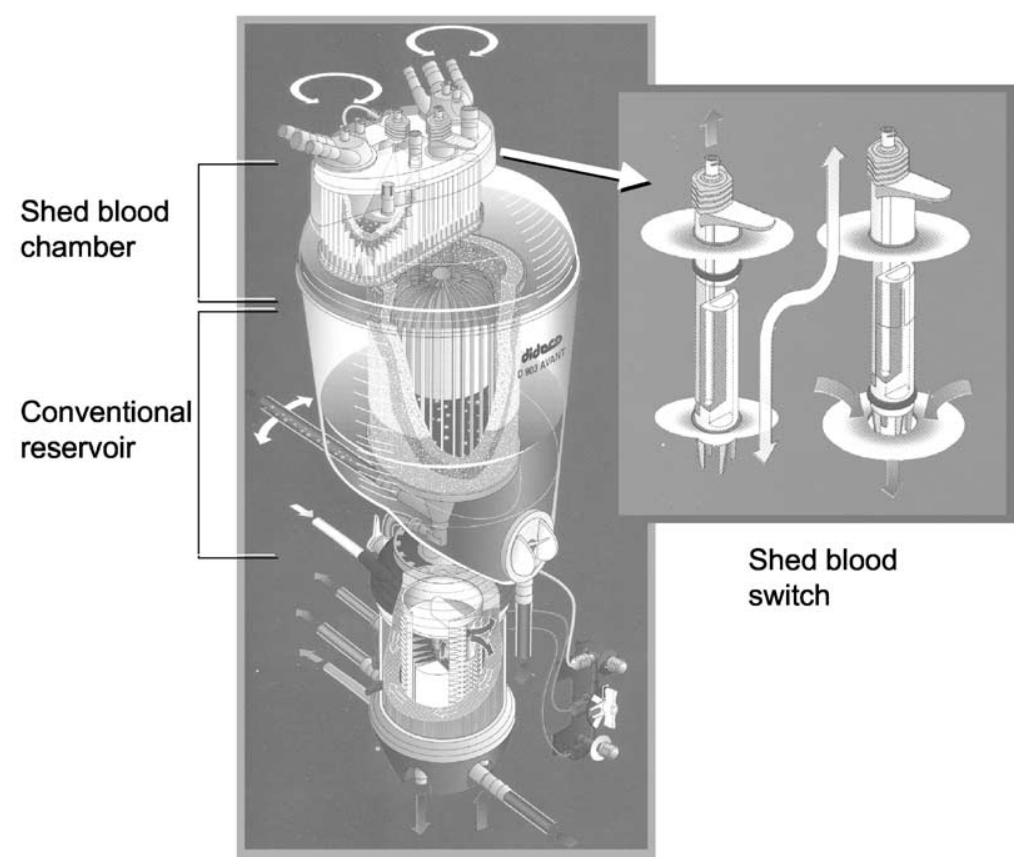

Figure 1. Shed blood separation system: schematic view of the shed blood separation system integrated in the reservoir of the extracorporeal circulation. Note the switch (insert) provided to guarantee direct recirculation in case of urgent volume demand. Upward movement of the column results in drainage of separated blood accumulated in the upper chamber into the conventional reservoir (lower chamber).

in the CPB was delivered via a roller pump and a heat exchanger at $4{ }^{\circ} \mathrm{C}$. After revascularization weaning from CPB was performed in the typical fashion. Thereafter, all patients received 1:1 protamine to antagonize heparin. The thorax was closed and the patient was transferred to the intensive care unit (ICU). The erythrocytes processed in the cell saver were substituted directly after arrival on the ICU. Drainage loss was measured using the calibration of a closed evacuation system (PLEUR-EVAC Sahara; Genzyme GmbH, Neu-Isenburg, Germany).

\section{Specific Extracorporeal Circulation Modalities}

Shed blood separation used in the ECCSBS group as well as in the CECCSBS group was performed with the aforementioned cardiotomy reservoir (AVANT D970). The simple system consists of a reservoir with a separation chamber positioned on top of the main chamber. Sucked blood is drained into the separation chamber and runs freely through it into the main chamber as long as separation is not desired. If separation is indicated, the connecting tube is mechanically closed so that the blood remains in the separation chamber (Figure 1). In case of an acute volume demand the connecting tube can be reopened at any time, which was not necessary in the study. After weaning from CPB the separated shed blood was processed in a cell saver together with conventionally aspirated blood from the operating field. In the CECCSBS group a tip-to-tip coating of all components was used comprising a phosphorylcholine (PHISIO, Dideco, Inc) coating of all tubes as well as the cannulas, oxygenator, and filter.

\section{Postoperative Therapy}

Weaning from ventilation was performed within the following 6 to 12 hours. The patients were then transferred from the ICU to the normal ward. Changes in electrocardiogram and myocardial enzymes were frequently monitored to detect perioperative myocardial infarction. All patients operated on with CPB remained in the hospital for 12 to 18 days while MIDCAB patients remained for 5 to 8 days.

\section{Laboratory Assessment}

In all extracorporeal circulation groups arterial blood was drawn at 5 time points: preoperatively, intraoperatively (after institution of $\mathrm{CPB}$, after crossclamp release, directly after decannulation), and postoperatively (first postoperative day). In the noECC group blood was drawn at 3 time points (preoperatively, intraoperatively, and first postoperative day). Free hemoglobin was determined photometrically. Hemoglobin, erythrocyte count, and platelet count were analyzed with the automated Hematology Analyser K-500 (Sysmex, Norderstedt, Germany). For verification of platelet function von Willebrand factor in the plasma of the patients was tested against lyophilized donor platelets while ristocetin was added as an activator. Ristocetin-cofactor activity was analyzed with a commercially available agglutination test (Behring Coagulation Timer; Dade Behring, Marburg, Germany). The activity was described as percentage of normal activity obtained with pooled donor plasma. ${ }^{10,11}$ The coagulation parameters thrombin-antithrombin complex (TATc) and prothrombin fragments 1 and 2 $(\mathrm{F} 1+2)$ and the fibrinolysis parameter plasmin-antiplasmin com- 
TABLE 1. Demographic data

\begin{tabular}{|c|c|c|c|c|c|}
\hline Patients & noECC & ECC & ECCSBS & CECCSBS & $P$ values \\
\hline Age (years) & $54.3 \pm 14.1$ & $64.1 \pm 12.1$ & $61.3 \pm 11.2$ & $60.3 \pm 7.9$ & NS (.299) \\
\hline Involved vessels (no.) & $1.2 \pm 0.4$ & $2.7 \pm 0.5$ & $2.7 \pm 0.5$ & $2.7 \pm 0.7$ & $<.001$ \\
\hline $\mathrm{BMI}$ & $26 \pm 8$ & $27 \pm 4$ & $27 \pm 3$ & $26 \pm 3$ & NS \\
\hline $\mathrm{EF}(\%)$ & $59 \pm 16$ & $62 \pm 12$ & $61 \pm 11$ & $61 \pm 12$ & NS \\
\hline EuroSCORE & $2.6 \pm 2.2$ & $4.2 \pm 2.6$ & $4.6 \pm 1.8$ & $3.3 \pm 3.3$ & NS (.331) \\
\hline Distal anastomoses (no.) & 1 & $3.1 \pm 1.4$ & $3.7 \pm 0.8$ & $3.8 \pm 0.8$ & $<.001$ \\
\hline Bypass time (min) & - & $90 \pm 36$ & $98 \pm 18$ & $97 \pm 23$ & NS \\
\hline Cross-clamping-time (min) & - & $50 \pm 21$ & $47 \pm 13$ & $56 \pm 15$ & NS \\
\hline ICU stay (days) & $1.1 \pm 0.3$ & $1.6 \pm 1.4$ & $1.4 \pm 0.5$ & $1.5 \pm 0.9$ & NS \\
\hline Hospitalization (days) & $6.4 \pm 1.5$ & $15.8 \pm 2.6$ & $16.8 \pm 2.6$ & $15.7 \pm 3.3$ & $<.001$ \\
\hline
\end{tabular}

$B M I$, Body mass index; $E F$, left ventricular ejection fraction; $I C U$, intensive care unit; $N S$, not significant.

plex (PAPc) were analyzed by means of commercially available standard enzyme-linked immunosorbent assay techniques (TATc: Enzygnost thrombin-antithrombin complex micro; PAPc: Enzygnost plasmin $/ \alpha 2$-antiplasmin complex micro, F1+2: Enzygnost prothrombin fragment 1 and 2, Dade Behring, Marburg, Germany).

\section{Statistical Analysis}

Statistical analysis was performed using SPSS statistical package for Windows (Version 9.0, SPSS Inc, Chicago, Ill). Numeric variables with normal distribution were analyzed by means of analysis of variance (ANOVA) and post hoc comparisons with Tukey honestly significant difference adjustment. Non-normally distributed variables were analyzed by means of Kruskal-Wallis test and subsequent Mann-Whitney test. Categorical variables were analyzed by means of Pearson chi-square test and subsequent $\alpha$ adjustment. Data are shown as mean percentages or means \pm standard deviation (SD). Significance was assumed if $P<.05$. ANOVA/Kruskal-Wallis test $P$ values are shown or $t$ test/MannWhitney test $P$ values between specific groups are presented, respectively.

\section{Results}

\section{Demographic and Operative Data}

The majority of the patients were male $(\mathrm{n}=38)$. Patients who underwent a MIDCAB procedure (noECC) tended to be younger and appeared to have less comorbidities as assessed by EuroSCORE than the other cohorts, although the differences did not gain statistical significance. All patients had an uneventful postoperative course. Rethoracotomy for bleeding was necessary in 2 patients $(1$ in ECC group, 1 in CECCSBS group). None of the patients developed a postoperative myocardial infarction. Sternal refixation because of dehiscence was necessary in 1 patient (ECCSBS group). Transient, mild psychosis was seen in 5 of the patients (2 in ECC group, 2 in ECCSBS group, 1 in CECCSBS group). Major neurological events such as focal deficits did not occur. Hospitalization of the noECC patients was significantly shorter than in all other groups, although differences between the 3 groups operated upon with CPB were not observed (Table 1).

\section{Hematological Parameters}

In all groups preoperative mean erythrocyte count did not show significant differences. In all CPB groups erythrocyte count decreased significantly compared with noECC during extracorporeal circulation and remained decreased at the first postoperative day. Significant differences between the 3 CPB groups were not observed. Free hemoglobin increased during operation in all CPB groups, although it remained rather stable in the noECC group. However, both shed blood separation groups showed significantly lower levels than the conventional ECC group, while not differing significantly from the noECC group. Between CECCSBS and ECCSBS groups no significant differences were detected, although the lowest values were observed at the end of the operation in the CECCSBS group. Postoperatively, the values of all patients in the CPB group normalized without showing significant differences compared with noECC group, while in both ECCSBS and ECC groups the values were higher than in noECC and CECCSBS groups (Table 2).

\section{Platelet Count and Function}

In all groups including the noECC patients platelets decreased intraoperatively and remained lower than prior to operation at the first postoperative day. No significant differences were found between all 4 groups. Ristocetin-cofactor increased in both uncoated ECC groups during CPB and remained elevated postoperatively, whereas the noECC group remained entirely stable and the coated ECCSBS group showed only slight alterations. However, because of a rather high variance these differences did not gain statistical significance at the 5\% level (Table 3).

\section{Coagulation and Fibrinolysis Parameters}

TATc did not increase in the noECC group but increased in all extracorporeal circulation groups. However, distinct differences were found between all 3 CPB groups. Although ECC and ECCSBS groups showed a marked increase throughout the $\mathrm{CPB}$ period, an only moderate increment 
TABLE 2. Hematological parameters

\begin{tabular}{|c|c|c|c|c|c|}
\hline & Preoperative & $\begin{array}{l}\text { Intraoperative, after } \\
\text { CPB institution }\end{array}$ & $\begin{array}{l}\text { Intraoperative, after } \\
\text { crossclamp release }\end{array}$ & $\begin{array}{l}\text { Intraoperative, after } \\
\text { decannulation }\end{array}$ & $\begin{array}{c}\text { First postoperative } \\
\text { day }\end{array}$ \\
\hline \multicolumn{6}{|c|}{ Erythrocytes (T/I) } \\
\hline NoECC & $4.7 \pm 0.3$ & & $3.8 \pm 0.4$ & & $3.9 \pm 0.2$ \\
\hline ECC & $4.3 \pm 0.7$ & $3.3 \pm 1.0^{*}$ & $2.9 \pm 0.7^{*}$ & $2.7 \pm 0.6^{*}$ & $3.0 \pm 0.3^{*}$ \\
\hline ECCSBS & $4.5 \pm 0.6$ & $3.0 \pm 0.9^{*}$ & $2.7 \pm 0.4^{*}$ & $2.8 \pm 0.5^{*}$ & $2.9 \pm 0.3^{*}$ \\
\hline CECCSBS & $4.7 \pm 0.6$ & $3.3 \pm 1.0^{*}$ & $2.9 \pm 0.7^{*}$ & $2.7 \pm 0.6^{*}$ & $3.0 \pm 0.3^{*}$ \\
\hline \multicolumn{6}{|l|}{$\mathrm{fHb}(\mu \mathrm{mol} / \mathrm{L})$} \\
\hline NoECC & $2.9 \pm 1.4$ & & $3.4 \pm 1.1 \dagger$ & & $3.5 \pm 0.8$ \\
\hline ECC & $4.0 \pm 5.7$ & $13.3 \pm 10.9$ & $18.1 \pm 8.3$ & $16.8 \pm 11.4$ & $6.4 \pm 5.8$ \\
\hline ECCSBS & $5.0 \pm 1.1$ & $5.8 \pm 4.2 \dagger$ & $8.7 \pm 4.2 \dagger$ & $10.3 \pm 3.5$ & $6.2 \pm 1.2$ \\
\hline CECCSBS & $4.5 \pm 6.3$ & $5.3 \pm 3.4 \dagger$ & $7.8 \pm 4.5 \dagger$ & $6.8 \pm 2.9 \dagger$ & $4.2 \pm 2.3$ \\
\hline
\end{tabular}

$C P B$, Cardiopulmonary bypass; $f H b$, free hemoglobin; $N S$, not significant.

${ }^{*} P<.05$ vs No ECC group.

$\dagger P<.05$ vs ECC group.

TABLE 3. Platelet count and function

\begin{tabular}{lccccc}
\hline & Preoperative & $\begin{array}{c}\text { Intraoperative, after } \\
\text { CPB institution }\end{array}$ & $\begin{array}{c}\text { Intraoperative, after } \\
\text { clossclamp release }\end{array}$ & $\begin{array}{c}\text { Intraoperative, after } \\
\text { decannulation }\end{array}$ & $\begin{array}{c}\text { First postoperative } \\
\text { day }\end{array}$ \\
\hline $\begin{array}{l}\text { Platelets (G/l) } \\
\text { noECC }\end{array}$ & $238 \pm 86$ & & & & \\
ECC & $210 \pm 57$ & $152 \pm 53$ & $195 \pm 107$ & & $181 \pm 60$ \\
ECCSBS & $210 \pm 70$ & $161 \pm 73$ & $139 \pm 52$ & $120 \pm 36$ & $177 \pm 127$ \\
CECCSBS & $231 \pm 84$ & $165 \pm 60$ & $158 \pm 64$ & $121 \pm 42$ & $142 \pm 49$ \\
Ristocetin cofactor (\%) & $153 \pm 58$ & $171 \pm 70$ & $147 \pm 58$ & $158 \pm 42$ \\
noECC & $196 \pm 85$ & $146 \pm 80$ & $154 \pm 67$ & & $141 \pm 71$ \\
ECC & $142 \pm 57$ & $95 \pm 41$ & $163 \pm 61$ & $242 \pm 127$ & $260 \pm 96^{*}$ \\
ECCSBS & $112 \pm 47$ & $111 \pm 49$ & $174 \pm 76$ & $218 \pm 71$ \\
CECCSBS & $153 \pm 65$ & $123 \pm 58$ & $147 \pm 55 \dagger$ & $185 \pm 66$ \\
\hline
\end{tabular}

$C P B$, Cardiopulmonary bypass. Ristocetin cofactor activity given in percent of the normal activity.

${ }^{*} P=.128$ vs NoECC group.

$\dagger P=.119$ vs ECC group.

was observed in the CECCSBS group. The ECC group revealed the highest levels at the time points after crossclamp release and after weaning from CPB, differing significantly from both ECCSBS and CECCSBS groups. At the first postoperative day the observed differences disappeared (Table 4, Figure 2).

$\mathrm{F} 1+2$ increased in both ECC and ECCSBS groups during extracorporeal circulation, while the values remained stable in noECC and CECCSBS groups. The ECC group, however, showed markedly increased peak levels differing from noECC group, CECCSBS group, and also from ECCSBS group. At the end of CPB CECCSBS and ECCSBS groups also showed statistical differences while no differences were found between noECC and CECCSBS groups. At the first postoperative day the values had normalized (Table 4).

PAPc exhibited corresponding findings. Although no increase was found in the noECC group as well as in the CECCSBS group, the ECC and ECCSBS groups reacted significantly with the time course of the $\mathrm{CPB}$, whereas no statistical difference was found between ECC and ECCSBS groups. Postoperatively, the differences diminished (Table 4, Figure 3).

Drainage Loss: Blood and Blood Product Substitution In the noECC group the least amount of postoperative drainage loss was observed. All CPB groups exhibited a higher amount of drainage fluid without showing significant differences. In the noECC group the least cumulative amounts of blood and fresh-frozen plasma units were substituted, although statistical differences with the CPB groups were not found (Table 5).

\section{Discussion}

\section{Extracorporeal Circulation}

Alteration of corpuscular elements of the blood during extracorporeal circulation is well recognized. ${ }^{12}$ A variety of factors such as shear stress, nonbiological surface contact, and temperature contribute to this phenomenon, which increases with extracorporeal circulation time. ${ }^{3,4}$ As early as 


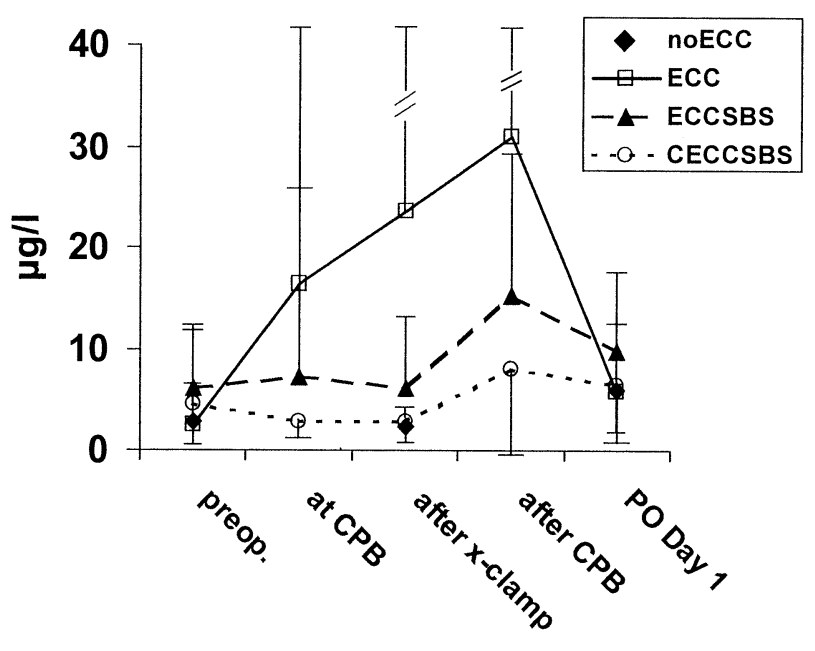

Figure 2. Thrombin-antithrombin complex $(\mu \mathrm{g} / \mathrm{L})$ of the noECC, ECC, ECCSBS, and CECCSBS groups. Data obtained at the 5 time points: preoperatively (preop.), intraoperatively after CPB institution (at CPB), after crossclamp release (after $x$-clamp), after decannulation (after CPB), at the first postoperative day (PO day 1). Data are presented as mean $\pm S D$.

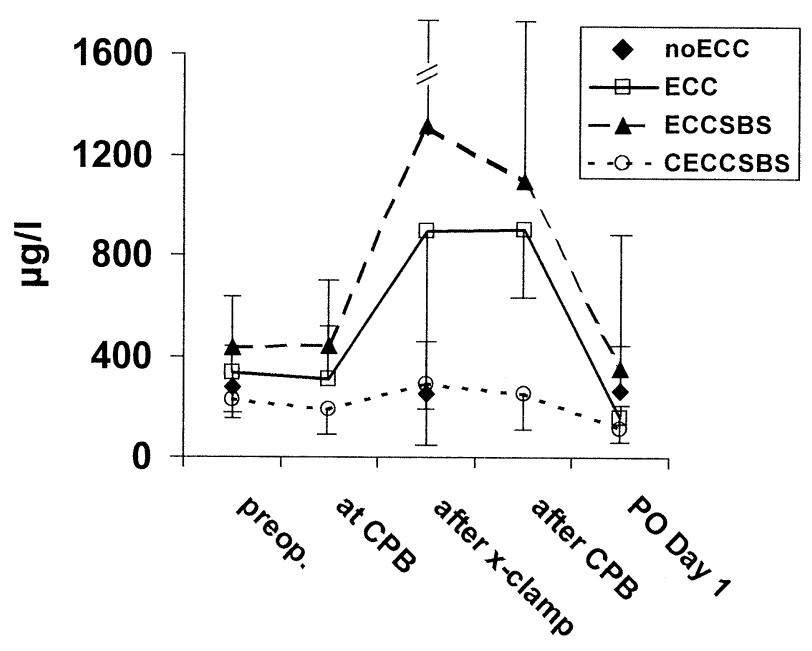

Figure 3. Plasmin-antiplasmin complex ( $\mu \mathrm{g} / \mathrm{L})$ of the noECC, ECC, ECCSBS, and CECCSBS groups. Data obtained at the 5 time points: preoperatively (preop.), intraoperatively after CPB institution (at CPB), after crossclamp release (after $x$-clamp), after decannulation (after CPB), at the first postoperative day (PO day 1). Data are presented as mean \pm SD.

TABLE 4. Coagulation and fibrinolytic parameters

\begin{tabular}{|c|c|c|c|c|c|}
\hline & Preoperative & $\begin{array}{l}\text { Intraoperative, after } \\
\text { CPB institution }\end{array}$ & $\begin{array}{l}\text { Intraoperative, after } \\
\text { crossclamp release }\end{array}$ & $\begin{array}{l}\text { Intraoperative, after } \\
\text { decannulation }\end{array}$ & $\begin{array}{c}\text { First postoperative } \\
\text { day }\end{array}$ \\
\hline \multicolumn{6}{|l|}{ TATc $(\mu \mathrm{g} / \mathrm{L})$} \\
\hline NoECC & $2.5 \pm 1.5$ & & $2.4 \pm 0.6 \dagger$ & & $6 \pm 2.6$ \\
\hline ECC & $6.1 \pm 4.7$ & $16.4 \pm 12.5$ & $23.7 \pm 19.5$ & $31.1 \pm 15.8$ & $5.8 \pm 2.4$ \\
\hline ECCSBS & $4.6 \pm 3.5$ & $7.3 \pm 9.8^{*}, \dagger$ & $6.1 \pm 4.1 \dagger$ & $15.3 \pm 7.8 \dagger, \ddagger$ & $9.8 \pm 4.2$ \\
\hline CECCSBS & $2.9 \pm 1.5$ & $2.8 \pm 1.2^{*}$ & $2.8 \pm 1.0 \dagger$ & $8.1 \pm 4.8 \dagger$ & $6.5 \pm 3.7$ \\
\hline \multicolumn{6}{|c|}{ Prothrombin fragments 1 and 2 (nmol/L) } \\
\hline NoECC & $1.7 \pm 0.5$ & & $1.6 \pm 0.5$ & & $1.7 \pm 0.7$ \\
\hline ECC & $1.4 \pm 0.6$ & $1.9 \pm 0.6$ & $2.7 \pm 1.0^{*}$ & $3.9 \pm 1.0^{*}$ & $1.3 \pm 0.4$ \\
\hline ECCSBS & $1.7 \pm 0.6$ & $1.5 \pm 0.6$ & $1.6 \pm 0.6 \dagger$ & $2.6 \pm 1.1 \dagger^{* *}$ & $2.0 \pm 0.7$ \\
\hline CECCSBS & $1.5 \pm 0.9$ & $0.9 \pm 0.5 \dagger$ & $0.9 \pm 0.4 \dagger$ & $1.2 \pm 0.4 \dagger, \S$ & $1.4 \pm 1.4$ \\
\hline \multicolumn{6}{|l|}{ PAPc $(\mu \mathrm{g} / \mathrm{L})$} \\
\hline NoECC & $275 \pm 128$ & & $253 \pm 99$ & & $262 \pm 174$ \\
\hline ECC & $337 \pm 148$ & $309 \pm 183$ & $895 \pm 832$ & $898 \pm 367^{*}$ & $159 \pm 128$ \\
\hline ECCSBS & $434 \pm 213$ & $442 \pm 326$ & $1317 \pm 1092^{*}$ & $1098 \pm 665^{*}$ & $351 \pm 577$ \\
\hline CECCSBS & $227 \pm 111$ & $190 \pm 100 \S \S$ & $292 \pm 192 \S$ & $250 \pm 154 \dagger, \S$ & $116 \pm 56$ \\
\hline
\end{tabular}

$C P B$, Cardiopulmonary bypass, $T A T c$, thrombin-antithrombin complex; PAPC, plasmin-antiplasmin complex.

${ }^{*} P<.05$ vs NoECC group.

${ }^{*} P=.085$ vs NoECC group.

$\dagger P<.05$ vs ECC group.

$\ddagger P=.07$ vs ECC group.

$\S P<.05$ vs ECCSBS group.

$\S \S P=.055$ vs ECCSBS group.

1979, however, cardiotomy suction has been identified to enhance cellular damage. ${ }^{13}$ Later, however, it was shown that red cell deformability, which was supposed to be the consequence of a mechanical trauma, was not caused by extracorporeal circulation itself but rather by mediators accumulated during prolonged blood pooling. ${ }^{14}$ It was instead shown that platelets and leukocytes are more likely to be damaged by mere mechanical forces such as roller or centrifugal pumps. ${ }^{12,15}$ Parallel to the investigations regarding the mechanical trauma many studies focused on the effect of $\mathrm{CPB}$ on the activation of coagulation cascades. ${ }^{16}$ It could be clearly shown that coagulopathy was 
TABLE 5. Drainage loss; blood and blood product substitution

\begin{tabular}{|c|c|c|c|c|c|}
\hline Patients & noECC & ECC & ECCSBS & CECCSBS & $P$ value \\
\hline Drainage loss (mL) & $446 \pm 222$ & $666 \pm 154$ & $639 \pm 151$ & $683 \pm 258$ & NS (.069) \\
\hline Blood units (U) & $0.7 \pm 0.9$ & $1.1 \pm 1.9$ & $1.3 \pm 2.4$ & $0.7 \pm 1.0$ & NS \\
\hline FFP (U) & $0.4 \pm 1.3$ & $0.7 \pm 1.0$ & $0.3 \pm 0.6$ & $0.8 \pm 1.9$ & NS \\
\hline
\end{tabular}

$F F P$, Fresh-frozen plasma; NS, not significant.

mediated by extracorporeal circulation and its time course. ${ }^{17}$ Much effort has been undertaken to reduce the mechanical stress as well as the coagulation activation during $\mathrm{CPB} .{ }^{18}$

\section{Coating}

Several investigators have focused on a coating system of the CPB components to disguise the foreign surface. As a consequence, different modalities have evolved. ${ }^{6,7}$ Heparin coating appeared to be a reasonable option, although most recent results were not entirely encouraging. ${ }^{19,20}$ As an alternative, a phosphorylcholine coating was developed. It is considered to mimic the biological endothelial surface because phosphorylcholine is an integral component of the cell membrane. ${ }^{7}$ The first studies indeed showed positive effects of such a coating. Therefore, phosphorylcholine coating has been clinically introduced. ${ }^{7}$

\section{Shed Blood Recirculation}

It was observed that suction of pooled pleural blood into the cardiotomy reservoir and its recirculation resulted in a variety of detrimental effects. Liberation of prostacyclin and prostaglandin E2 in shed blood resulted in a marked decrease of the systemic blood pressure after recirculation. ${ }^{8}$ Other detrimental effects of shed blood have been identified as induced by lipid microembolization, ${ }^{21}$ activated complement, ${ }^{22}$ or cytokine release of pooled leukocytes. ${ }^{23}$ The important clinical consequence of an increased postoperative blood loss because of an activation of fibrinolysis and platelet dysfunction in shed blood has already been demonstrated. ${ }^{24}$ Therefore, avoidance of shed blood recirculation has been propagated to minimize these effects. Unfortunately, the amount of blood drained from the operating field can be high. A considerable loss of autologous blood therefore occurs. As an avenue out of this dilemma, a shed blood separation system was developed. The separated shed blood can be processed in a cell saver to retrieve the red blood cells for subsequent administration while potentially detrimental humoral factors are eliminated. ${ }^{1,5,21-23}$

\section{Study}

In summary of the literature, both coating and shed blood separation appeared to be beneficial in terms of a reduction of cellular alteration and humoral activation. We therefore conducted a clinical study to elucidate these effects. As a control, we chose a MIDCAB instead of an off-pump coronary artery bypass (OPCAB) procedure because it represents an off-pump coronary revascularization technique with a minor operative trauma. Because a median sternotomy was not performed, liberation of bone marrow fat and subsequent activation of inflammatory parameters such as cytokines or arachidonic acid metabolites was avoided. Otherwise, MIDCAB patients exhibited sufficient similarities with the other groups because they suffered from arteriosclerosis, underwent almost identical anesthesia, and received acetylsalicylic acid as well as heparin and protamine. All ECC patients were submitted to a standard low-dose aprotinin protocol. A recent study showed that low-dose aprotinin did not inhibit the inflammatory response and coagulation caused by cardiopulmonary bypass as assessed by TATc. A reduction of fibrinolyis assessed by PAPc, however, was observed. ${ }^{25}$

\section{Red Blood Cells}

In our study we found supporting evidence for the data published in the literature as well as both investigated strategies. The global erythrocyte count decreased only moderately in all CPB groups. Free hemoglobin, in contrast, was markedly increased in the conventional ECC group while it was much less elevated in both shed blood separation groups. The combination of coating and shed blood separation, however, exhibited the least damage.

\section{Platelets}

In our study we did not find statistical proof for an effect of shed blood separation and coating on platelet morphology and function. However, some trends were observed and can be interpreted carefully in the light of the results already demonstrated in the literature. The total number of platelets did not exhibit significant findings aside from a moderate decrease in all groups including the MIDCAB patients, although we expected a normal platelet count in our MID$\mathrm{CAB}$ procedures because of the absence of $\mathrm{CPB}$ and the moderate blood loss. Von Willebrand factor-ristocetin cofactor correlates with platelet aggregation in high shear stress situations such as extracorporeal circulation ${ }^{10,11}$ and was therefore chosen to assess platelet function in this study. Indeed, platelet function appeared to be less altered in the coated CPB group. One could therefore assume a ben- 
eficial effect of phosphorylcholine coating on platelet function, which has already been demonstrated by others. ${ }^{7}$ Heparin alone and in combination with protamine can alter platelet function and induce fibrinolysis ${ }^{26}$ although chronic pretreatment with acetylsalicylic acid may have reduced this phenomenon in our study. However, our findings supported the hypothesis that platelet consumption by activation, aggregation, and clearance can be triggered by the various drug interactions during anesthesia. ${ }^{1}$

\section{Coagulation and Fibrinolysis}

The analysis of coagulatory and fibrinolysis parameters exhibited a detrimental effect of conventional extracorporeal circulation. In conventional ECC both coagulation and fibrinolysis were markedly elevated, although shed blood separation alone was beneficial in terms of a reduction of coagulation disturbances but not fibrinolysis. The combination of coating and shed blood separation was followed by the least pronounced effects of coagulation and fibrinolysis in our study. We expected a down-regulation of fibrinolysis in all ECC groups because of the standard low-dose aprotinin protocol, which was uniformly applied. ${ }^{25}$ The remaining extent of fibrinolysis in both uncoated groups, however, underlines the benefit of coating with phosphorylcholine in terms of a reduction of fibrinolysis. In this regard one can speculate that in the coated groups a reduction of circulating fibrin monomers may have contributed to a partial neutralization of plasmin activity.

\section{Blood Loss and Substitution}

One of the important clinical consequences of a reduced activation of coagulation cascades, as well as alteration of blood cells due to mechanical forces, may be the amount of perioperative drainage as well the necessity for blood and blood product substitution. ${ }^{26}$ Our results demonstrated that drainage loss was higher in all CPB groups than in the MIDCAB patients. However, statistical evidence was not seen. Both the MIDCAB patients as well as the group with shed blood separation and coating required less substitution of blood than the other CPB groups. Again, these differences did not reach statistical significance.

\section{Study Limitations}

In our study the isolated impact of phosphorylcholine coating was not investigated. Other clinical studies, however, have already been conducted and exhibited positive effects of phosphorylcholine coating on coagulation. ${ }^{6,7}$ The specific CPB modalities investigated by us did not serve the purpose of saving blood in our study, although the observed trends may gain statistical relevance in a larger trial.

\section{Conclusion}

We conclude from this first investigation that phosphorylcholine coating in combination with shed blood separation reduced mechanical alteration of red blood cells and coagulation disturbances in routine CPB procedures to a level otherwise only seen in off-pump procedures. The separated blood can be processed in a cell saver for later substitution, thereby avoiding excessive blood loss.

\section{References}

1. Laffey JG, Boylan JF, Cheng DCH. The systemic inflammatory response to cardiac surgery. Anesthesiology. 2002;97:215-2.

2. Kawahito K, Mohara J, Misawa Y, Fuse K. Platelet damage caused by centrifugal pump: in vitro evaluation by measuring the release of alpha-granule packing proteins. Artif Organs. 1997;21:1105-9.

3. Weiland AP, Walker WE. Physiologic principles and clinical sequelae of cardiopulmonary bypass. Heart Lung. 1986;15:34-9.

4. Whitten CW, Hill GE, Ivy R, Greilich PE, Lipton JM. Does the duration of cardiopulmonary bypass or aortic crossclamp, in the absence of blood and/or blood product administration, influence the IL-6 response to cardiac surgery? Anesth Analg. 1998;86:28-33.

5. Schonberger JP, Everts PA, Hoffmann JJ. Systemic blood activation with open and closed venous reservoirs. Ann Thorac Surg. 1995;59: 1549-55.

6. Yu K, Lamba NMK, Courtney JM, et al. Polymeric biomaterials: influence of phosphorylcholine polar groups on protein adsorption and complement activation. Int J Artif Organs. 1994;17:499-504.

7. De Somer F, Francois K, van Oeveren W, et al. Phosphorylcholine coating of extracorporeal circuits provides natural protection against blood activation by the material surface. Eur J Cardiothorac Surg. 2000;18:602-6.

8. Lavee J, Naveh N, Dinbar I, Shinfeld A, Goor DA. Prostacyclin and prostaglandin E2 mediate reduction of increased mean arterial pressure during cardiopulmonary bypass by aspiration of shed pulmonary venous blood. J Thorac Cardiovasc Surg. 1990;100:546-51.

9. Axford TC, Dearani JA, Ragno G, et al. Safety and effectiveness of reinfused shed blood after open heart surgery. Ann Thorac Surg. 1994;57:615-22.

10. Veyradier A, Fressinaud E, Boyer. Neumann C, Trossaert M, Meyer D. von Willebrand factor ristocetin cofactor activity correlates with platelet function in a high shear stress system. Thromb Haemost 2000;84:727-8.

11. Goto S, Tamura N, Handa S, Arai M, Kodama K, Takayama H. Involvement of glycoprotein VI in platelet thrombus formation on both collagen and von Willebrand factor surfaces under flow conditions. Circulation. 2002;106:266-72.

12. Mulholland JW, Massey W, Shelton JC. Investigation and quantification of the blood trauma caused by the combined dynamic forces experienced during cardiopulmonary bypass. Perfusion. 2000;15:485-94.

13. Wright G, Sanderson JM. Cellular aggregation and trauma in cardiotomy suction systems. Thorax. 1979;34:621-8.

14. Lohrer RM, Trammer AR, Dietrich W, Hagl S, Linderkamp O. The influence of extracorporeal circulation and hemoseparation on red cell deformability and membrane proteins in coronary artery disease. J Thorac Cardiovasc Surg. 1990;99:735-40.

15. Bergman P, Belboul A, Friberg LG, al-Khajya N, Mellgren G, Roberts D. The effect of prolonged perfusion with a membrane oxygenator (PPMO) on white blood cells. Perfusion. 1994;9:35-40.

16. Hunt BJ, Parratt RN, Segal HC, Sheikh S, Kallis P, Yacoub M. Activation of coagulation and fibrinolysis during cardiothoracic operations. Ann Thorac Surg. 1998;65:712-8.

17. Yilmaz M, Haznedaroglu IC, Kirazli S, Pasaoglu I. Effects of extracorporeal circulation on thrombin-antithrombin III and prothombin fragment 1+2 levels. Clin Appl Thromb Hemost. 2002;8:61-3.

18. Harig F, Feyrer R, Mahmoud FO, Blum U, von der Emde J. Reducing the post-pump syndrome by using heparin-coated circuits, steroids, or aprotinin. Thorac Cardiovasc Surg. 1999;47:111-8.

19. Sinci V, Kalaycioglu S, Gunaydin S, Imren Y, Gokoz L, Soncul H, Ersoz A. Evaluation of heparin-coated circuits with full heparin dose strategy. Ann Thorac Cardiovasc Surg. 1999;5:156-63.

20. Butler J, Wurithi EW, Pathio VL, MacArthur KJD, Berg GA. Duroflo 
II heparin bonding does not attenuate cytokine release or improve pulmonary function. Ann Thorac Surg. 2002;74:139-42.

21. Kincaid EH, Jones TJ, Stump DA, et al. Processing scavenged blood with a cell saver reduces cerebral lipid micorembolization. Ann Thorac Surg. 2000;70:1296-300.

22. Arnestadt JP, Hyllmer M, Bengston JP, Tylman M, Mollnes TE Bengtsson A. Removal of activated complement from shed blood: comparison of high- and low-dilutional haemofiltration. Acta Anaesthesiol Scand. 1998;42:811-5.

23. Schmidt H, Bendtzen K, Mortensen PE. The inflammatory response after autotransfusion of shed mediastinal blood. Acta Anaesthesiol Scand. 1998;42:558-64.
24. de Haan J, Schnberger J, Han J, van Oeveren W, Eijgelaar A. Tissue-type plasminogen activator and fibrin monomers synergistically cause platelet dysfunction during retransfusion of shed blood after cardiopulmonary bypass. J Thorac Cardiovasc Surg. 1993; 106:1017-23.

25. Englberger L, Kipfer B, Berdat PA, Nydegger UE, Carrel TP. Aprotinin in coronary operation with cardiopulmonary bypass: does "lowdose" aprotinin inhibit the inflammatory response? Ann Thorac Surg. 2002;73:1897-904.

26. Khuri SF, Valeri CR, Loscalzo J, et al. Heparin causes platelet dysfunction and induces fibrinolysis before cardiopulmonary bypass. Ann Thorac Surg. 1995;60:1008-14. 